Ying Xiao · Dawoon Jung • Tamara Gund •

Sanjay V. Malhotra

\title{
An experimental and theoretical study of the enantioselective deprotonation of cyclohexene oxide with isopinocampheyl-based chiral lithium amides
}

Received: 9 May 2005 / Accepted: 2 March 2006 / Published online: 17 May 2006

C) Springer-Verlag 2006

\begin{abstract}
The mechanism of the enantioselective deprotonation of cyclohexene oxide with isopinocampheyl-based chiral lithium amide was studied by quantum chemical calculations. The transition states of eight molecules were fully optimized at the ab initio $\mathrm{HF} / 3-21 \mathrm{G}$ and density functional B3LYP/3-21G levels with Gaussian 98. The activation energies were calculated at the B3LYP/6-31+G (3df,2p)//B3LYP/3-21G level. We found the theoretical evaluation to be consistent with the experimental data. At the best case, an enantiomeric excess of up to $95 \%$ for $(R)$ 2-scyclohexen-1-ol was achieved with (-)- $N, N$-diisopinocampheyl lithium amide.
\end{abstract}

Keywords Theoretical study - Enantioselective deprotonation - Cyclohexene oxide $\cdot$ Chiral lithium amides - Density functional activation energy · B3LYP/6-31+G(3df,2p)

\section{Experimental data}

Lithium amides are an important class of reagents in organic synthesis and have been used extensively as strong bases for various reactions [1-3]. The deprotonation of an epoxide with a lithium amide to obtain an allylic alcohol was first reported in 1970 in a deuterium-labeling study by Thummel and Rickborn [4]. The reaction is thought to

Dedicated to Professor Dr. Paul von Ragué Schleyer on the occasion of his 75 th birthday.

Electronic Supplementary Material Supplementary material is available for this article at http://dx.doi.org/10.1007/s00894-0060114-2

Y. Xiao $\cdot$ D. Jung $\cdot$ T. Gund $\cdot$ S. V. Malhotra $(\bowtie)$ Department of Chemistry and Environmental Science, New Jersey Institute of Technology, University Heights, Newark, NJ 07102, USA

e-mail: malhotra@njit.edu proceed via a cyclic six-membered transition state, formed by a 1:1 epoxide to base complex, where the base coordinates to the lone pair of electrons on oxygen, thereby facilitating the $\beta$-hydrogen removal. On the other hand, if a prochiral epoxide is deprotonated with a chiral lithium amide, it could give an optically active product. Such a rationale was first proposed over two decades ago, for a nonenzymatic "asymmetric deprotonation" of cyclohexene oxide to obtain 2-cyclohexen-1-ol (Scheme 1) [5].

Over the years, a number of different chiral lithium amides have been designed and used for various deprotonation reactions [6]. As a result, asymmetric synthesis using chiral lithium amides has emerged as a useful method for the preparation of nonracemic compounds [7-11]. The methodology offers the advantage that the chiral auxiliaries can be recycled easily, thereby making the process effective and cost efficient. These chiral lithium bases have been exploited by a variety of efficient enantioselective reactions. Considering the remarkable success of pinene-based reagents for various organic transformations $[12,13]$, we synthesized a set of chiral secondary amines derived from $\alpha$-pinene (Scheme 2) (Malhotra and Brown 1998, unpublished results).

The lithium salts of these amines were tested in the deprotonation of meso-epoxides [14]. Diisopinocampheylamine (DIPAM) prepared from $(+)-\alpha$-pinene has the advantage of $\mathrm{C}_{2}$-symmetry. $\mathrm{N}$-cyclohexyl- $\mathrm{N}$-isopinocampheylamine (ChxIPAM), $N$-benzyl- $N$-isopinocampheylamine (BzIPAM) and $N$-isopropyl- $N$-isopinocampheylamine ('PIPAM) were chosen to study the steric effect of the isopinocampheyl moiety in the deprotonation of a mesoepoxide to allylic alcohol. Reaction with a stoichiometric amount of DIPAM gave the product with $>99 \%$ enantiomeric excess (EE) on deprotonation of cyclohexene oxide.

To generate a catalytic cycle $[15,16]$ (Scheme 3), numbers of achiral lithium amides were compared with chiral amines for the opening of meso-epoxides. Lithium diisopropylamide (LDA) emerged as the achiral amide of choice because first, the chiral amine could be regenerated easily, and secondly, due to the fact that there was a significant difference in the rate of competitive reactions 


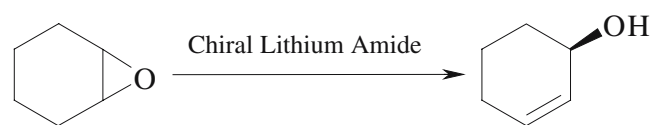

Scheme 1 Asymmetric deprotonation of cyclohexene oxide

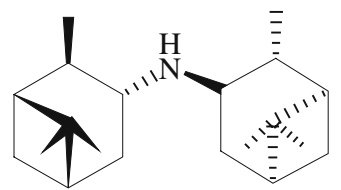

(DIPAM)

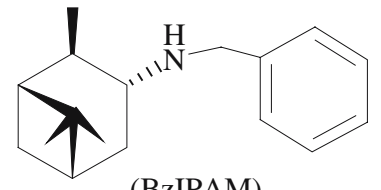

(BzIPAM)

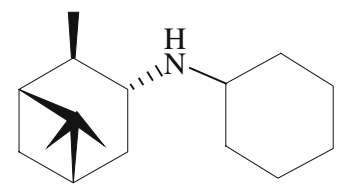

(ChxIPAM)

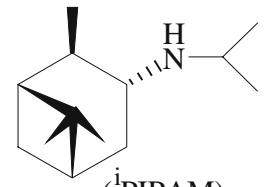

$\left({ }^{\mathrm{i}}\right.$ PIPAM)
Scheme 2 Four kinds of lithium amides

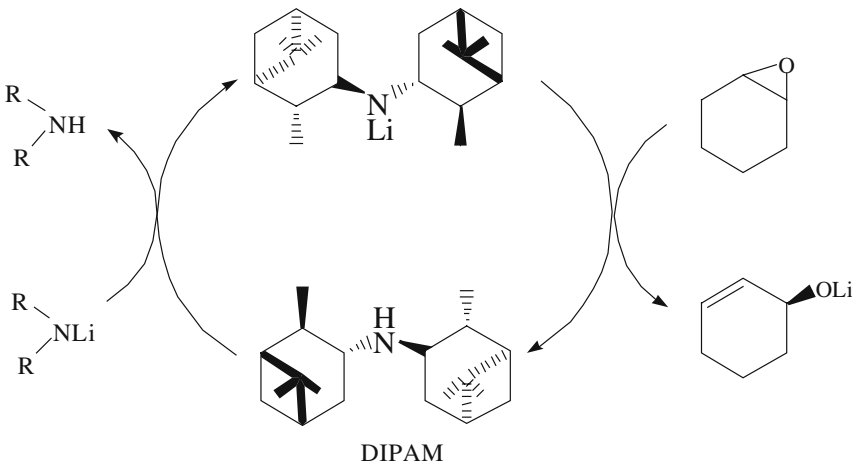

Scheme 3 Reaction flow chart with the chiral amides, i.e., when two amides (achiral and chiral) were present together, the deprotonation of the epoxide was mainly due to the chiral amide. Also, a systematic investigation with varied amounts of chiral amine DIPAM, and at different temperatures revealed that the best results could be obtained at $0{ }^{\circ} \mathrm{C}$ using $20 \mathrm{~mol} \%$ of the chiral and $125 \%$ of the achiral amines.

The results of the deprotonation of meso-cyclohexene oxide with various chiral amides are shown in Table 1 .

The experimental data clearly indicate that the isopinocampheyl moiety is the key to obtaining high yields and EEs.

\section{Theoretical calculations}

Successful rationalizations of enantioselectivity depend on comprehensive knowledge about the reaction mechanism $[17,18]$. To verify the experimental results shown in Table 1, we embarked on a theoretical calculation of the deprotonation reaction of cyclohexene oxide using Gaussian 98. The possible reaction routes for deprotonation of cyclohexene oxide with various chiral amides are shown in Scheme 4.

First, all transition states for reactions with various chiral amines were located and optimized by ab initio HF/3-21G and density functional $\mathrm{B} 3 \mathrm{LYP} / 3-21 \mathrm{G}$ calculations with Gaussian 98. The deprotonation of the epoxide with lithium amide occurs via a six-membered ring transition state, where lithium approaches the lone pair of electrons on oxygen, thus facilitating the removal of the $\beta$ hydrogen. As shown in Fig. 1a, in the case of deprotonation with DIPAM-Li (R1 optimized with B3LYP/3-21G), when

Table 1 Catalytic enantioselective deprotonation of cyclohexene oxide 1

\begin{tabular}{|c|c|c|c|c|c|c|}
\hline Entry & Amine & Mol (\%) & Temperature & Yield $(\%)^{\mathrm{a}}$ & $\operatorname{EE~}(\%)^{b}$ & Config $^{\mathrm{c}}$ \\
\hline 1 & DIPAM & 5 & $0{ }^{\circ} \mathrm{C}(\mathrm{rt})$ & $59(62)$ & $80(77)$ & $R$ \\
\hline 2 & DIPAM & 10 & $0{ }^{\circ} \mathrm{C}(\mathrm{rt})$ & $66(68)$ & $81(74)$ & $R$ \\
\hline 3 & DIPAM & 15 & $0{ }^{\circ} \mathrm{C}(\mathrm{rt})$ & $69(73)$ & $83(79)$ & $R$ \\
\hline 4 & DIPAM & 20 & $0{ }^{\circ} \mathrm{C}(\mathrm{rt})$ & $77(82)$ & $95(87)$ & $R$ \\
\hline 5 & DIPAM & 25 & $0{ }^{\circ} \mathrm{C}(\mathrm{rt})$ & 78 (79) & $89(83)$ & $R$ \\
\hline 6 & ChxIPAM & 5 & $0{ }^{\circ} \mathrm{C}$ & 55 & 65 & $R$ \\
\hline 7 & ChxIPAM & 10 & $0{ }^{\circ} \mathrm{C}$ & 57 & 74 & $R$ \\
\hline 8 & ChxIPAM & 15 & $0{ }^{\circ} \mathrm{C}$ & 66 & 76 & $R$ \\
\hline 9 & ChxIPAM & 20 & $0{ }^{\circ} \mathrm{C}$ & 70 & 78 & $R$ \\
\hline 10 & BzIPAM & 5 & $0{ }^{\circ} \mathrm{C}$ & 51 & 34 & $R$ \\
\hline 11 & BzIPAM & 10 & $0{ }^{\circ} \mathrm{C}$ & 53 & 39 & $R$ \\
\hline 12 & BzIPAM & 15 & $0{ }^{\circ} \mathrm{C}$ & 58 & 46 & $R$ \\
\hline 13 & BzIPAM & 20 & $0{ }^{\circ} \mathrm{C}$ & 57 & 48 & $R$ \\
\hline 14 & ${ }^{\mathrm{i}}$ PIPAM & 5 & $0{ }^{\circ} \mathrm{C}$ & 50 & 43 & $R$ \\
\hline 15 & ${ }^{\mathrm{i}}$ PIPAM & 10 & $0{ }^{\circ} \mathrm{C}$ & 51 & 47 & $R$ \\
\hline 16 & ${ }^{\mathrm{i}}$ PIPAM & 15 & $0{ }^{\circ} \mathrm{C}$ & 55 & 51 & $R$ \\
\hline 17 & ${ }^{1}$ PIPAM & 20 & $0{ }^{\circ} \mathrm{C}$ & 58 & 52 & $R$ \\
\hline
\end{tabular}

${ }^{\text {a Isolated yield }}$

${ }^{\mathrm{b}} \mathrm{EE}$ of the (R)-MTPA ester derivative [20, 21]

${ }^{\mathrm{c}}$ Assignment based on the sign of optical rotation 
Scheme 4 The deprotonation reaction equations of cyclohexene oxide

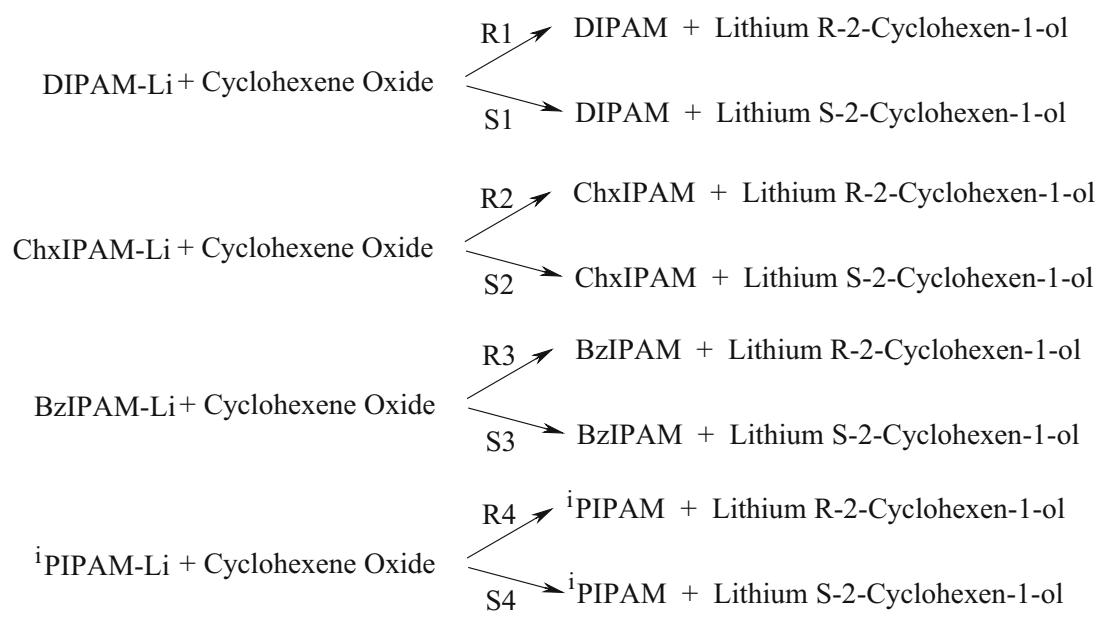

* R1, R2, R3, R4 and S1, S2, S3, S4 are signals of transition states
Fig. 1 a Six-membered ring transtion states. b The $(R)$ and $(S)$ transition states for the deprotonation reactions shown in Scheme 4
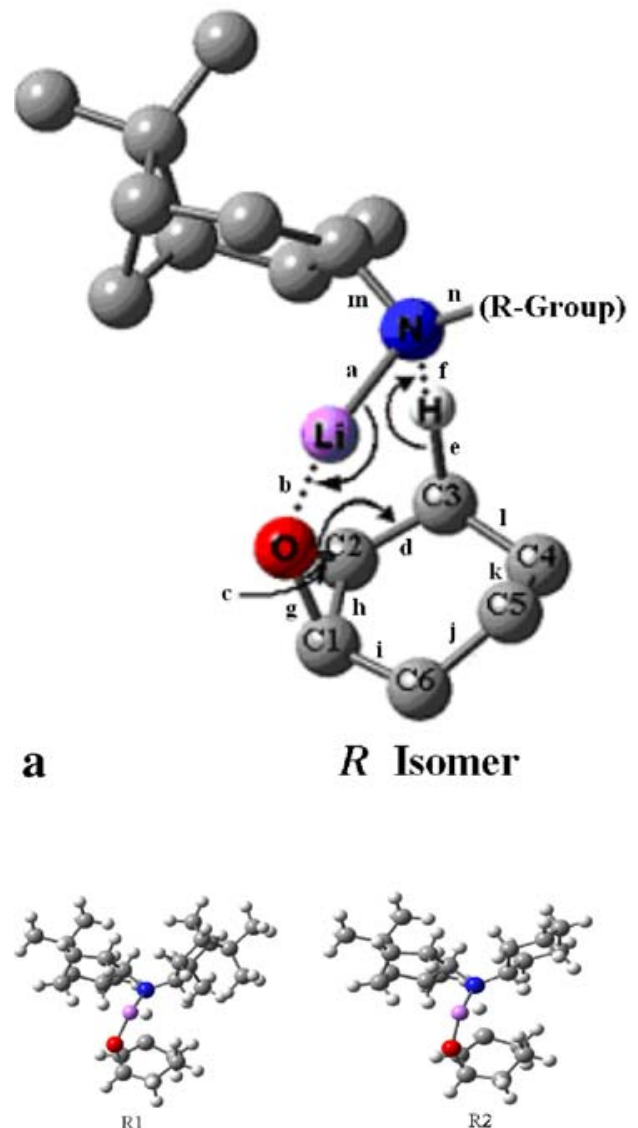

b
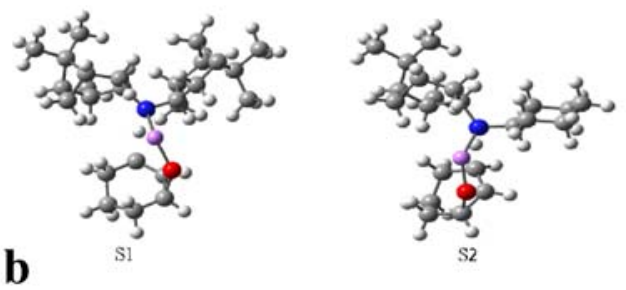
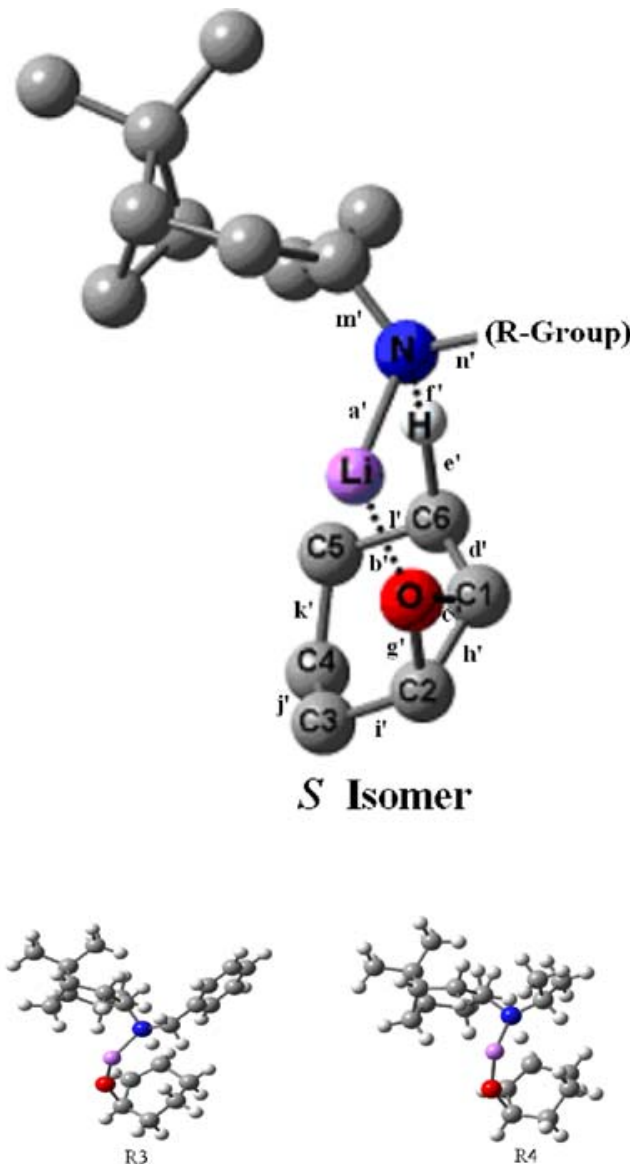

$S$ Isomer
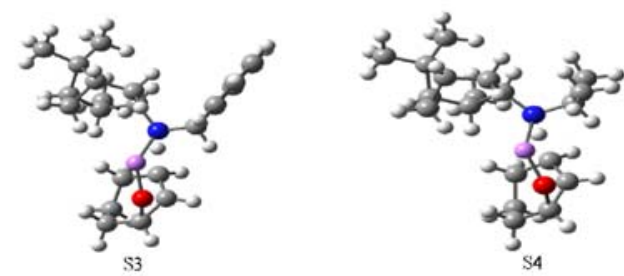
Table 2 Important bond distances in optimized transition states

\begin{tabular}{|c|c|c|c|c|c|c|c|c|}
\hline \multirow[t]{2}{*}{ Bond } & \multicolumn{4}{|l|}{$\mathrm{HF} / 3-21 \mathrm{G}$} & \multicolumn{4}{|l|}{ B3LYP/3-21G } \\
\hline & $\begin{array}{l}\text { T.S. of } \\
\text { DIPAM } \\
\text { Distance }(\AA)\end{array}$ & $\begin{array}{l}\text { T. S. of } \\
\text { ChxIPAM } \\
\text { Distance }(\AA)\end{array}$ & $\begin{array}{l}\text { T. S. of } \\
\text { BzIPAM } \\
\text { Distance }(\AA)\end{array}$ & $\begin{array}{l}\text { T. S. of } \\
\text { iPIPAM } \\
\text { Distance }(\AA)\end{array}$ & $\begin{array}{l}\text { T.S. of } \\
\text { DIPAM } \\
\text { Distance }(\AA)\end{array}$ & $\begin{array}{l}\text { T. S. of } \\
\text { ChxIPAM } \\
\text { Distance }(\AA)\end{array}$ & $\begin{array}{l}\text { T. S. of } \\
\text { BzIPAM } \\
\text { Distance }(\AA)\end{array}$ & $\begin{array}{l}\text { T. S. of } \\
\text { iPIPAM } \\
\text { Distance }(\AA)\end{array}$ \\
\hline $\mathrm{a}\left(\mathrm{a}^{\prime}\right)$ & $1.89(1.90)$ & $1.89(1.89)$ & $1.89(1.90)$ & $1.89(1.89)$ & $1.87(1.87)$ & $1.86(1.87)$ & $1.87(1.87)$ & $1.86(1.86)$ \\
\hline $\mathrm{b}\left(\mathrm{b}^{\prime}\right)$ & $1.74(1.76)$ & $1.73(1.73)$ & $1.73(1.73)$ & $1.73(1.73)$ & $1.74(1.73)$ & $1.73(1.73)$ & $1.72(1.72)$ & $1.73(1.73)$ \\
\hline $\mathrm{c}\left(\mathrm{c}^{\prime}\right)$ & $1.64(1.58)$ & $1.66(1.62)$ & $1.65(1.60)$ & $1.66(1.62)$ & $1.84(1.83)$ & $1.85(1.83)$ & $1.86(1.84)$ & $1.85(1.84)$ \\
\hline$d\left(d^{\prime}\right)$ & $1.46(1.47)$ & $1.45(1.46)$ & $1.46(1.47)$ & $1.45(1.46)$ & $1.44(1.44)$ & $1.44(1.44)$ & $1.44(1.44)$ & $1.44(1.44)$ \\
\hline $\mathrm{e}\left(\mathrm{e}^{\prime}\right)$ & $1.44(1.48)$ & $1.43(1.46)$ & $1.45(1.48)$ & $1.43(1.46)$ & $1.24(1.25)$ & $1.24(1.25)$ & $1.24(1.25)$ & $1.24(1.24)$ \\
\hline $\mathrm{f}\left(\mathrm{f}^{\prime}\right)$ & $1.32(1.29)$ & $1.33(1.30)$ & $1.31(1.29)$ & $1.32(1.30)$ & $1.59(1.57)$ & $1.62(1.57)$ & $1.60(1.56)$ & $1.62(1.59)$ \\
\hline $\mathrm{g}\left(\mathrm{g}^{\prime}\right)$ & $1.47(1.49)$ & $1.46(1.47)$ & $1.47(1.48)$ & $1.46(1.47)$ & $1.47(1.47)$ & $1.47(1.47)$ & $1.47(1.47)$ & $1.47(1.47)$ \\
\hline $\mathrm{h}\left(\mathrm{h}^{\prime}\right)$ & $1.46(1.47)$ & $1.46(1.46)$ & $1.46(1.46)$ & $1.46(1.46)$ & $1.48(1.48)$ & $1.48(1.48)$ & $1.48(1.48)$ & $1.48(1.48)$ \\
\hline $\mathrm{i}\left(\mathrm{i}^{\prime}\right)$ & $1.51(1.51)$ & $1.51(1.51)$ & $1.51(1.51)$ & $1.51(1.51)$ & $1.52(1.53)$ & $1.52(1.53)$ & $1.52(1.53)$ & $1.52(1.53)$ \\
\hline $\mathrm{j}\left(\mathrm{j}^{\prime}\right)$ & $1.54(1.54)$ & $1.53(1.54)$ & $1.53(1.54)$ & $1.53(1.54)$ & $1.54(1.54)$ & $1.54(1.54)$ & $1.54(1.54)$ & $1.54(1.54)$ \\
\hline $\mathrm{k}\left(\mathrm{k}^{\prime}\right)$ & $1.54(1.54)$ & $1.54(1.54)$ & $1.54(1.54)$ & $1.54(1.54)$ & $1.54(1.54)$ & $1.54(1.54)$ & $1.54(1.54)$ & $1.54(1.54)$ \\
\hline $1\left(1^{\prime}\right)$ & $1.54(1.54)$ & $1.54(1.55)$ & $1.54(1.54)$ & $1.54(1.55)$ & $1.54(1.55)$ & $1.54(1.54)$ & $1.54(1.55)$ & $1.54(1.55)$ \\
\hline $\mathrm{m}\left(\mathrm{m}^{\prime}\right)$ & $1.49(1.48)$ & $1.49(1.48)$ & $1.49(1.48)$ & $1.49(1.48)$ & $1.50(1.49)$ & $1.50(1.49)$ & $1.50(1.49)$ & $1.50(1.49)$ \\
\hline $\mathrm{n}\left(\mathrm{n}^{\prime}\right)$ & $1.48(1.49)$ & $1.48(1.48)$ & $1.48(1.48)$ & $1.48(1.48)$ & $1.49(1.50)$ & $1.49(1.50)$ & $1.48(1.49)$ & $1.49(1.49)$ \\
\hline
\end{tabular}

lithium approaches the lone pair electrons on oxygen, the $\mathrm{N}-\mathrm{Li}$ bond is stretched to $1.870 \AA$ (from $1.750 \AA$ ). As a result, the $\mathrm{C}-\mathrm{O}$ bond $(1.840 \AA)$ is broken. Furthermore, the $\beta \mathrm{C}-\mathrm{H}$ bond is stretched from 1.080 to $1.240 \AA$ and then broken. The transition states for $(R)$ and $(S)$ isomers obtained with different ligands are shown in Fig. 1b. When the " $\beta$ hydrogen" is deprotonated from the C-3 atom of cyclohexene oxide, the transition states result in the $R$ configuration, and the product is $(R)$-2-cyclohexen-1-ol. On the other hand, if the " $\beta$ hydrogen" is deprotonated from the C-6 atom of cyclohexene oxide, the transition states give the $S$ configuration, thereby $(S)$-2-cyclohexen$1-$ ol is obtained. The selected bond distances of the transition state $(R$ and $S)$ structures were optimized using ab initio HF/3-21G and density-functional B3LYP/3-21G calculations. The changed bond distances are shown in Table 2. The first imaginary frequency shown in the
Appendix explains that ab initio HF and density-functional B3LYP methods with the 3-21G-basis set were successful in finding transition states in this study.

As Fig. 1 and Table 2 show, the bond distances varied with different $R$-groups. $R$ isomers have absolutely the same atoms as $S$ isomers, but the bond distances are different. Bonds a, b, c, d, e, f or a' $\mathrm{a}^{\prime} \mathrm{b}^{\prime}, \mathrm{c}^{\prime}, \mathrm{d}^{\prime}, \mathrm{e}^{\prime}$, and $\mathrm{f}^{\prime}$ are most important for locating the transition states. Bond $\mathrm{g}-\mathrm{n}$ or $\mathrm{g}^{\prime}-\mathrm{n}^{\prime}$ did not change much in various transition state structures.

The total energies in Hartree at $0 \mathrm{~K}$ for the reactants and transition states obtained by way of single-point calculations on the B3LYP/3-21G optimized geometries using a modern SCRF/PCM [19] implementation are shown in Table 3. The solvent in the SCRF calculations is tetrahydrofolate (THF), which is the same as used in the experiments.

Table 3 The energies for all transition states and reactants in Hartree at $0 \mathrm{~K}$

\begin{tabular}{|c|c|c|c|c|}
\hline \multirow[t]{2}{*}{ Amine } & \multicolumn{4}{|c|}{ B3LYP/6-31+G(3df,2p)//B3LYP/3-21G (Hartree) } \\
\hline & $\mathrm{R}$ figuration & $\mathrm{S}$ figuration & $(\mathrm{S})-(\mathrm{R})$ & (S)-(R) kcal mol ${ }^{-1}$ \\
\hline DIPAM & $(\mathrm{R} 1)-1152.031094$ & $(\mathrm{~S} 1)-1152.024281$ & 0.006813 & 4.275 \\
\hline ChxIPAM & $(\mathrm{R} 2)-996.847617$ & $(\mathrm{~S} 2)-996.840595$ & 0.007022 & 4.406 \\
\hline BzlPAM & (R3) -1031.810112 & $(\mathrm{~S} 3)-1031.802679$ & 0.007433 & 4.664 \\
\hline${ }^{\mathrm{i}}$ PIPAM & $(\mathrm{R} 4)-879.958785$ & $(\mathrm{~S} 4)-879.951436$ & 0.007349 & 4.612 \\
\hline DIPAM-Li & -842.197713 & & & \\
\hline ChxIPAM-Li & -687.015267 & & & \\
\hline BzlPAM-Li & -721.984766 & & & \\
\hline iPIPAM-Li & -570.132208 & & & \\
\hline Cyclohexene Oxide & -309.889039 & & & \\
\hline
\end{tabular}


Table 4 Activation energies calculated by B3LYP/6-31+G(3df,2p)// B3LYP/3-21G

\begin{tabular}{lll}
\hline Amine & \multicolumn{2}{l}{ Activation energy } \\
\cline { 2 - 3 } & Hartree & $\mathrm{kcal} \mathrm{mol}^{-1}$ \\
\hline DIPAM & 0.055658 & 34.926 \\
ChxIPAM & 0.056689 & 35.573 \\
BzIPAM & 0.063693 & 39.968 \\
${ }^{i}$ PIPAM & 0.062462 & 39.196 \\
\hline
\end{tabular}

All transition states correspond to $R$ configuration products

As the calculation and data in Table 3 show, the transition state energy for $R$ isomer is lower than the $S$ isomer in each case. Hence, the transition states for the $R$ products are more stable and therefore easier to obtain. The energy differences between the transition states for the $R$ and $S$ structures were also calculated. However, all computed $(S)$ $(R)$ energies in Table 3 correspond to $>99 \%$ ee, which did not reflect the observed experimental selectivities. The activation energies can be calculated by subtracting the sum of the energies of reactants from the energy of the corresponding transition state. For example:

$$
\begin{aligned}
\text { Activation Energy of DIPAM } & =\mathrm{R} 1-(\mathrm{DIPAM}-\mathrm{Li}+\text { Cyclohexene Oxide }) \\
& =-1152.031094-(-842.197713)+(-309.889039) \\
& =0.055658\left(\mathrm{Hartree}^{-}\right) \\
0.055658 * 627.5095 & =34.926\left(\mathrm{kcal} \mathrm{mol}^{-1}\right)
\end{aligned}
$$

The activation energies were calculated at the density functional B3LYP level with the 6-31+G(3df,2p) basis set. We only calculated the $R$ configuration structures and the data for $R$ configuration are shown in Table 4. Similarly, the calculations for the $S$ configuration structures could use the same method. One thing that should be pointed out in this study is that the monomeric Li-amide may be a poor model for the substrates in solution because of its tendency to form higher aggregates.

In the case of reaction with the chiral amine DIPAM, the activation energy obtained is the lowest. This reaction can occur selectively and rapidly, resulting in high EE and yield of product. Substituting one isopinocampheyl group in DIPAM with cyclohexyl leads to higher activation energy for the reaction to occur. Similarly, substitution with a benzyl or isopropyl group also gives increased reaction energy, resulting in lower product yield and EE. We also note that with the benzyl group, the relative activation energies are highest, which means that this kind of reaction is the most difficult. Therefore, lower yields and EE for this product should be obtained, as is the case in Table 1. These theoretical calculations confirm the experimental findings that the isopinocampheyl moiety plays an important role in orienting the epoxide and the lithium salt in such way that the deprotonation takes place very enantioselectively.

\section{Conclusion}

The mechanism of the enantioselective deprotonation of cyclohexene oxide with isopinocampheyl-based chiral lithium amide was examined at the B3LYP/6-31+G (3df,2p)//B3LYP/3-21G levels using Gaussian 98. We uncovered the mechanistic details of the catalytic cycle, which are supported well by the experimental results. The highest EE (95\%) for the conversion of cyclohexene oxide to 2-cyclohexen-1-ol has been achieved with lithium DIPAM through the catalytic system. These theoretical and experimental results certainly promise the catalytic application of DIPAM and similar pinene-based ligands in the complex synthesis of natural products and biologically important compounds.

Acknowledgements We thank Professor Joseph Bozzelli for letting us use the cluster PCs and quantum mechanical programs. The Molecular Modeling Laboratory used in this study was funded jointly by the NSF Grant No 9750809 and New Jersey Institute of Technology.

\section{References}

1. Koga K (1995) New Methods Drug Res 4:25-27

2. O'Brien P (1998) J Chem Soc Perkin Trans 1:1439-1457

3. Simpkins NS (1996) Asymmetric deprotonation reactions using enantiopure lithium amide bases. In: Stephenson GR (ed) Advanced asymmetric synthesis. Blackie, Glasgow, Scotland, pp 111-125

4. Thummel RP, Rickborn B (1970) J Am Chem Soc 92: 2064-2067

5. Whitesell JK, Felman SW (1980) J Org Chem 45:755-756

6. Simpkins NS (2000) Chimia 54:53-54

7. Cox PJ, Simpkins NS (1991) Tetrahedron: Asymmetry 2:1-26

8. Simpkins NS (1996) Pure Appl Chem 68:691-694

9. Jones S (2002) J Chem Soc Perkin Trans 1:1-21

10. O'Brien P (2001) J Chem Soc Perkin Trans 1:95-113

11. Koga K (1994) Pure Appl Chem 66:1487-1492

12. Brown HC, Kramer GW, Levy AB, Midland MM (1975) Organic synthesis via Boranes. Wiley, New York

13. Brown HC, Ramachandran PV (1996) Sixty years of hydride reductions. In: Abdel-Magid AF (ed) Reductions in organic synthesis. American Chemical Society, Washington, DC, pp $1-30$

14. Malhotra SV (2003) Tetrahedron: Asymmetry 14:645-647 
15. Asami M (1985) Tetrahedron Lett 26:5803-5806

16. Asami M, Ishizaki T, Inoue S (1994) Tetrahedron: Asymmetry 5:793-796

17. Toukoniitty E, Nieminen V, Taskinen A, Paivarinta J, Hotokka M, Murzin DY (2004) J Catal 224:326-339

18. Brandt P, Hedberg C, Lawonn K, Pinho P, Andersson PG (1999) Chem Eur J 5:1692-1699
19. Foresman JB, Keith TA, Wiberg KB, Snoonian J, Frisch MJ (1996) J Phys Chem 100:16098-16104

20. Sodergren MJ, Andersson PG (1998) J Am Chem Soc 120: 10760-10761

21. Gayet A, Bertilsson S, Andersson PG (2002) Org Lett 4: 3777-3779 